\title{
Public sector information and re-use - where is the UK now?
}

\author{
Stephen Saxby \\ School of Law, \\ Faculty of Law, Arts and Social Sciences, \\ Southampton University, \\ Highfield, Southampton, SO17 1BJ, UK \\ E-mail: S.J.Saxby@soton.ac.uk
}

\begin{abstract}
Information produced by the government does of course serve a number of purposes. First, it should inform the government so as to generate sound policy decisions and effective strategies. Second, through a variety of media, it should provide the general public with information to enable individuals to engage with government services and to deliver personal data that they are obliged to provide. Access to a wide variety of public sector information (PSI) is also important for individuals and businesses. In the UK, this has been under debate for many years through analysis of Crown copyright regulation. Current policy, as interpreted by the HM Treasury, continues to argue that those wishing to exploit or add value to PSI for commercial purposes should at least contribute something to the cost of its supply. This paper traces the process of development of the policy through to the present.
\end{abstract}

Keywords: public sector information; PSI; re-use policy; PSI Directive; Crown copyright; trading funds; public access; Office of Public Sector Information; OPSI; UK PSI Regulations.

Reference to this paper should be made as follows: Saxby, S. (2008) 'Public sector information and re-use - where is the UK now?', Int. J. Private Law, Vol. 1, Nos. 3/4, pp.229-255.

Biographical notes: Prof. Stephen Saxby, (BA, Cert.Ed., MBCS, PhD, Solicitor) University of Southampton, is the Editor of The Computer Law and Security Review - The International Journal of Technology Law and Practice (Elsevier), http://www.compseconline.com, and The Encyclopedia of Information Technology Law (Sweet and Maxwell). He is also a Professor of IT Law and Public Policy at Southampton and the Deputy Head of School. He specialises in e-government, public information and geospatial policy in the UK.

\section{Introduction}

The origins of Crown copyright can be traced back to the 16th and 17th century controls on printing in which the Court of Star Chamber and subsequently the state claimed the right to supervise the publication of works of all kinds. Apart from the retention of separate prerogative powers governing the printing of the King James Bible and the Book of Common Prayer, ${ }^{1}$ such rights were subsequently narrowed to a limited category of 
official publications as defined by legislation. Although the Whitford Committee ${ }^{2}$ proposed the abolition of Crown copyright in the build up to the 1988 Copyright Designs and Patents Act (c.48), it was retained where 'a work is made by Her Majesty or by an officer or servant of the Crown in the course of his duties'. ${ }^{3}$ This applies whether or not the ordinary qualifying requirements are satisfied. In addition, the act introduced a separate Parliamentary copyright for works 'made by or under the direction or control of the House of Commons or the House of Lords'. ${ }^{4}$

In assessing policy towards the treatment of official information prior to the onset of information and communications technology (ICT), one can observe a situation where the government is effectively in control of the distribution of such material. Up to this point, there was no political will strong enough to shake the foundations of a system by which the government and Parliament were the custodians and controllers of the information they created. These institutions were largely free to introduce their own systems and rules for determining what public access to grant and under what terms such information could be reproduced. However, the sudden ease with which information of all kinds could be released online through the internet has raised public expectations that official information would soon be more open and accessible too. This new state of mind is very much in tune with the lobby that ultimately was successful in pressing for a statutory freedom of information right for the UK with the passage of the Freedom of Information Act 2000 (c.36).

\section{The commercial exploitation of official information}

\subsection{The early years of the policy}

It is quite apparent that, by the time 'government.direct' was published in November 1996, the government had already accepted the value of the internet for the delivery of basic information to the public about the government and departmental services, and was rapidly moving on to look more carefully at how transactional services, beyond mere information provision, might be entered into electronically. ${ }^{5}$ At the same time, it was also clear that, as part of the move towards greater efficiency, the government was also developing its thinking regarding the commercial exploitation of public information.

The starting point for any discussion of the latter issue is Crown and Parliamentary copyrights. Works originating within the government commissioned and assigned to it have Crown copyright, with Parliamentary copyright vesting in works made by or under the direction and control of either the House of Parliament. ${ }^{6}$ Exercising its intellectual property rights, the Crown had, for many years, sought 'to off-set the costs of some of its operations through charging commercial rates for certain tradable information-based services'. ${ }^{7}$ In 1996-1997, the government reported revenues in the sum of $£ 199$ million arising from such distribution including direct sales income, licensing revenues and income from data supply. Of the 76 departments or agencies originating the material, more than $88 \%$ of the revenues derived from seven cost centres, ${ }^{8}$ and $73 \%$ of this income came from fees charged for public searches made at HM Land Registry, Trade and Industry as well as the sale of mapping products, navigational charts and publications and meteorological products. ${ }^{9}$ Altogether, only $15 \%$ of the total income reported by the government over that period represented a sales based royalty, where a department or 
agency published material via a commercial publisher, or licensed publishers, organisations or individuals to reproduce Crown copyright material.

In analysing these figures, it is apparent that the government was deriving less than $£ 30$ million per annum from its licensing and royalty agreements at that time. In broad explanation of the position, the Green Paper pointed to the fact that policy towards Crown copyright was under review implying that the drift towards liberalisation (non-enforcement) of Crown copyright for some classes of material would reduce such income. It also suggested that, while it was important to 'secure the revenue which departments obtain for providing high-quality services for which the customer is willing to pay a price', it should also be understood that 'we want to provide the public and the information industry with easier and quick access to the general run of material produced and held by the government'. ${ }^{10}$

Two years later, the HM Treasury's cross cutting review of the knowledge economy ${ }^{11}$ did report a $70 \%$ increase to $£ 340$ million in total income from publishing Crown copyright information, including information available only under licensing arrangements. However, almost all (92\%) of this income was accrued by trading fund operators. $^{12}$ Of the top five earners, only the Office of National Statistics was not a trading fund.

Government policy towards the publication of official material has been, with the exception of Acts of Parliament, statutory instruments and certain other Parliamentary papers, to leave the arrangements for first publication to the department that originated the material. Such authority was delegated by HMSO's copyright unit, whose supervisory function was retained when the printing and publishing element of its original responsibilities were diverted to the newly privatised company - The Stationery Office Ltd. - in $1996 .{ }^{13}$ For some time prior to these changes, delegation of authority by HMSO to departments was limited. However, gradual acceptance that the private sector would have a contribution to make to the process led to the production of 'Tradable Information Guidelines' - first published in September 1986. A second edition was produced in $1990^{14}$ and this encouraged departments to seek out data and information that might be suitable for use by the information industry within commercial electronic information services. The 'guidelines' envisaged that tradable information might include information already processed and used by the government to be re-used in the same context by the private sector; information to which the private sector wanted to process themselves and add 'value'; and information collected by the government for one purpose, resold to the private sector for other purposes. HMSO, as 'legal owner' of all Crown copyright material was to be a party to any agreement and informed when negotiations were underway.

It is clear that the 1990 'guidelines' recognised implicitly that the government held large amounts of information and that it was important, economically, that such information be available in a form in which it could be useful. Information was 'a commodity' which had value and this should be exploited. Although the 'guidelines' had identified a strategy and a process for potential collaboration with the information industry, the private sector was generally unimpressed with the end product. In the 1980s and 1990s, in the period leading up to the publication of the Green Paper on Crown copyright in $1998,{ }^{15}$ commercial publishers had become increasingly frustrated with the diversity of departmental policy on tradable information and the licensing bureaucracy that accompanied it. Although a series of 'dear publisher' letters were published, offering 
more detailed guidance on a range of publishing, copyright and access issues, and although some discussion had taken place between HMSO and the industry, elements of it declared themselves to be generally dissatisfied and sidelined by the process that was being operated. This is now set out in the Office of Public Sector Information (OPSI) Guidance. $^{16}$

Conflict also surfaced on occasions between the negotiating parties. In one case, the Inland Revenue, entered into an exclusive licensing arrangement with commercial publisher Tolleys, for the printing and distribution of tax guidance manuals. HMSO had also apparently granted licences to Butterworths and a CD-Rom producer for printed and electronic versions of the work. Under the threat of litigation alleging Crown copyright infringement, the matter was settled and permission granted to HMSO's licensees to proceed with publication subject to a Crown copyright notice appearing in the work.

In addition to the difficulties over the so-called tradable information, licensing restrictions were also applied in respect of other types of Crown copyright material. For example, reproduction (as opposed to photocopying) of statutory publications and press releases could only be reproduced in a 'value-added' content i.e., 'where the official text has had value added to it by compilation, with other related text, analysis, commentary, annotation, indexing or cross-referencing'. ${ }^{17}$ This would apply to both commercially published and in-house databases within an organisation. ${ }^{18}$ Different licensing and charging structures were also applied according to whether the reproduction was to be in print or non-print media, mere extracts or substantial full text or, for certain Parliamentary copyright material, a particular category of work such as a bill or select committee report or an extract from Hansard. ${ }^{19}$

A central feature of the debate between the information industry and the government was the impact of Crown copyright on the exploitation of the public sector information (PSI). Publishers pointed to the more liberal regime in the USA where copyright was not asserted in respect of government information or court judgements. Legislation there in $1995^{20}$ ensured that exclusive licensing arrangements between agencies and publishers, the levying of fees above dissemination cost for access, or the placement of controls over the commercial exploitation and resale of such data would be prohibited unless specifically provided for by a statute. It was argued that this 'diversity approach', whereby official information was treated as a national resource and generally made available for dissemination without restriction, had been beneficial to the growth of the US electronic publishing sector, which in turn had generated a number of significant benefits for the US economy.

In February 1996, the 'conservative' government announced the establishment of the Information Society Initiative - the primary objective of which was to exploit the business benefits of ICT. This added a further dimension to the existing ten year Citizen's Charter programme, commenced in 1991 and re-launched in June 1997 by the 'labour' government, designed to modernise and improve the quality of public services. At the same time, the lobby was well underway to develop a 'Freedom of Information' policy in Britain to secure more open the government. It was in the context of these initiatives that the incoming government decided to continue with the review of Crown copyright first announced in November 1996 by the then Chancellor of the Dutchy of Lancaster Roger Freeman. ${ }^{21}$ The objective of the review, as initially stated, was to facilitate 'the growth of new information services both in printed and electronic formats, in line with the government's policy of maximising public access to official information and subject to 
the continuing need to protect the taxpayer's interest and the integrity of Crown copyright materials, ${ }^{22}$

The product of that review was the Green Paper of January 1998 - 'Crown copyright in the information age'. ${ }^{23}$ The review team comprised officials from a number of relevant government departments and agencies which, in addition to its consultation with other parts of the government also spoke to 'numerous private sector interests and professional bodies ${ }^{24}$ The report did not deal with publication on the internet, but concentrated upon an assessment of the nature and purpose of Crown copyright, the relationship between the government and the private sector in respect of the publication of official material and the need, if at all, for the retention of Crown copyright. It noted that departments and agencies were increasingly publishing material on the internet with some developing their own commercial publishing operations. Most departments now granted first publication rights to private sector publishers with the terms dependent on an assessment of the nature of the work and anticipated sales. Works thus produced that had a strong market potential would attract a royalty to the department. Other less marketable publications would not attract a royalty demand so, in these cases, the publisher would bear the risk, but would retain the sales income in full. Sometimes, a subsidy would be sought prior to publication. In the case of material produced by executive agencies, a variety of arrangements might apply to enable the latter to recover operating costs and remain self-financing as frequently required by the HM Treasury.

In March 1999, the government published a White Paper - 'the future management of Crown copyright', ${ }^{25}$ 'outlining' its response to the Green Paper and public comment on it. Responses had been submitted from business users, trade and professional bodies, private individuals, the academic and library community, the legal profession, public bodies and the media. With regard to the possible options for the future of Crown copyright, the White Paper concluded that commercial information providers favoured its abolition. This viewpoint suggested that information should be 'disseminated at cost with minimal or no controls, allowing market discipline to ensure the accuracy of the material'. ${ }^{26}$ Against that, however, was an apparent consensus among the relatively limited number of responses ${ }^{27}$ in favour of retention of Crown copyright, provided waivers and relaxations were introduced in respect of a number of categories of works, as well as the introduction of a centralised administration, common standards and scales of charges. The watchwords for the future would be 'coherence, transparency, access, simplification and liberalisation, ${ }^{28}$

Adhering to this approach, HMSO would retain overall control of Crown copyright, but licensing of protected material might devolve to the originating department where that material was of a specialised nature such as 'mapping, meteorological, scientific and statistical data'. ${ }^{29}$ Reproduction of certain categories of work such as primary and secondary legislation, government press notices and forms, consultative documents and those featured on departmental websites, certain statistical data and other published papers, would be freed from the need to obtain specific permission or licence provided its use was for a non-commercial purpose. Other material might be subject to standard forms of licensing that might be entered into online. Except in exceptional circumstances, exclusive licensing would be prohibited.

Turning to the issue of commercial usage, the White Paper confirmed that the government had no plans to relax the value-added requirement, already established, whereby commercial re-publishers of official material would first have to add value to it 
before permission to reproduce would be granted. This rule protected the public 'from confusion over the availability of works which purport to be replica works and which have the potential to mislead' ${ }^{30}$ It was also observed that the pre-condition would have an economic impact ensuring the 'financial viability of official published works'. ${ }^{31}$ Presumably, this was because additional private sector publication of such works in this form would, as a result of the pre-condition, be controlled. The requirement also 'underpinned commercial arrangements' between departments and private sector publishers competing under open tender. ${ }^{32}$

The White Paper also addressed the issue of tradable information and once more a definition was offered. This was information outside the categories to which value must first be added before commercial publishers could be permitted to reproduce. Whereas the latter, as illustrative of 'non-tradable' information, was the product of the government's core activities, tradable information was its by-product. Whether it had value added to it or was simply raw data gathered in, the fact that it happened to be produced by the government was incidental to its creation. That being the case different considerations applied compared to information which was more directly related to the function and purpose of the government. The White Paper envisaged five different publishing models for tradable information:

\begin{abstract}
"departments publish commercially material under their own imprint and sell via bookshops and distributors; ... departments choose to publish official or departmentally endorsed versions of works in various forms via private sector publishers; ... departments enter into joint venture publishing agreements with private or public sector partners to develop publications and products, often in electronic media, where investment costs and risks can be high; ...departments supply information to customers as part of an electronic service; and ... departments may provide a service whereby data is transferred directly in electronic form.”3
\end{abstract}

The government took the view that, whichever model applied, an element of cost recovery would reduce the burden on taxpayers. However, wider policy objectives, including the benefits of disseminating the material should also be taken into account when pricing the information. Some respondents supported a differential charging arrangement according to intended usage, but commercial respondents pointed to the difficulties of distinguishing between commercial and non-commercial exploitation. The government noted these comments committing it to charging levels that would reflect its stated aims. New guidelines on tradable information would be prepared as part of the government's Wider Markets Initiative (WMI) designed to 'provide a framework of policy and good practice for developing commercial activities using public sector assets'. ${ }^{34}$

\title{
2.2 Developments after the 1999 Green Paper
}

It is clear that, in the aftermath of the White Paper, efforts were being maintained, both by the government and the information industry, to deal with the problems that continued to concern both sides. From the government's point of view, it pointed to the establishment by HMSO at that time of a Crown Copyright User Group [renamed to the Advisory Panel on Public Sector Information (APPSI) in April 2003] with representatives drawn from a wide range of sectors. ${ }^{35}$ Its original function was to 'discuss the practical effects of implementing new policies on Crown copyright following the publication of 
the White Paper', ${ }^{36}$ but its terms of reference were later widened to coincide with its new title:

\begin{abstract}
"to advise Ministers on how to encourage and create opportunities in the information industry for greater re-use of PSI; advise the Director of OPSI and the Controller of HMSO about changes and opportunities in the information industry, so that the licensing of Crown copyright and PSI is aligned with current and emerging developments; and advise on the impact of the complaints procedures under the re-use of PSI Regulations 2005 and to review and consider complaints under those regulations."37
\end{abstract}

Among issues raised in the early days of the user group were tradable information, class licensing and charging policy. All sides at that time seemed to have accepted that the policy designed to encourage exploitation of tradable information had not worked and that more needed to be done to stimulate its development. The decision to establish an information asset register (IAR) ${ }^{38}$ was welcomed as a first step towards the creation of a comprehensive listing of an organisation's hitherto unpublished information. This is described as:
"a register of unpublished information holdings i.e., information or collections of information, held electronically or in hard copy, which have (usually) not been published or made publicly available. The IAR does not provide direct access to the information holdings themselves. It is a means of alerting the public to the existence of the unpublished information and whom to contact. Requests for the information will be dealt with in accordance with the Freedom of Information Act 2000. The IAR also supports initiatives to ensure the re-use of PSI. In this sense, it can be used by other government departments to identify information resources which may be of interest." ${ }^{39}$

Guidelines for the preparation of IAR records have since been published. ${ }^{40}$

While the IAR will define the nature, location and form of potentially exploitable information in a much clearer manner and generally provide a shop window for such content, this does not, in itself, resolve the economic and bureaucratic questions associated with its exploitation that have been consistently raised for a number of years now by the information industry. Efforts to tackle these fundamental issues have, since July 1998, been given added impetus following the Prime Minister's decision to set up the Strategy Unit within the Cabinet Office following an internal review of the effectiveness of the centre of government. ${ }^{41}$ The PIU and, since then, the Strategy Unit, has been charged with improving 'the capacity of the government to address strategic, cost cutting issues and to promote innovation in the development of policy and in the delivery of the government's objectives'. ${ }^{42}$ In addition, HMSO, the former Department of Trade and Industry (DTI) and officials from the HM Treasury began to discuss charging and licensing issues within Crown copyright regulation as part of the Wider Markets Guidance $^{43}$ announced by the treasury in December 2002. This guidance was designed to explain the government's policy for selling services into wider markets, including information. Analysis of how to move forward on 'tradable information' was subsequently swept up within the broader dimensions of these initiatives, which embraced the abolition in 2004 of the Office of the E-Envoy and its replacement within the Cabinet Office by the E-Government Unit (now the Delivery and Transformation Group) whose remit now is to coordinate and lead e-government and e-commerce strategic thinking. ${ }^{44}$ This is regarded as an evolution of the e-envoy's role in supporting public service reform. 
Original Guidance in 1998 proposed that government departments, agencies and non-departmental public bodies (NDPBs) should be 'encouraged to make better use of their assets and, where appropriate, within certain rules, by engaging in commercial services based on them'. The policy would apply 'to the commercial exploitation of physical assets, including equipment, land and premises, and non-physical assets: intellectual property, data and skills'. In addition, it indicated that departments, agencies and NDPBs should normally undertake more straightforward projects themselves, but many projects, 'particularly those which are larger and more complex, should be taken forward with the private sector'. Wider markets should be seen in large measure as one strand of wider policy on public private partnerships. ${ }^{45}$

In September 1999, the issue was analysed in a report from the $\mathrm{PIU}^{46}$ which advised the government to extend its discussion with the private sector over Crown copyright. The report welcomed the proposed framework for Crown copyright regulation announced in the White Paper, but concluded that 'the lack of a consistent approach across government' placed 'unnecessary burdens' on publishers seeking to resell government data. ${ }^{47}$ It recommended the development of class licensing arrangements as a replacement for specific licensing of Crown copyright material. Broadly speaking, this would offer standard terms and unrestricted access to any such material ending the practice of refusal to supply that some departments are operated. However, administration and pricing issues were not addressed.

In July 2001, the HM Treasury issued further guidance for government departments and other Crown bodies on the principles that should govern in charging for information which was subject to Crown copyright. The context for this was the implementation of the Freedom of Information Act 2000 and decisions arising from the 'Review of Government Information' of December of that year. ${ }^{48}$

The next stage in the process was the drafting of a proposed class licence by members of the then Crown Copyright User Group. While some information industry representatives within the group may have seen this as a positive step towards a more modern regime relating to UK Government data, some were clearly disappointed that support for some form of generalised waiver of Crown copyright was not forthcoming as acknowledged in the responses to the Green Paper. ${ }^{49}$ The PIU report made it clear that 'ensuring the integrity of government data and the ability for the government itself to trade in and add value to its information', ruled out any such consideration. ${ }^{50}$ The government's view was that the waiver outlined in chapter five of the White Paper ${ }^{51}$ represented the limit of what could be done within the policy parameters just outlined. The response from parts of the private sector was that even material within the scope of this waiver remained subject to Crown copyright regulation and 'guidance note' requirements and therefore offered only minimal relaxation. ${ }^{52}$

In 2003, work that had been underway within the APPSI and its predecessor on the development of a so-called 'Fair Trading Charter for Public Sector Information', led to the launch of the 'information fair trader scheme (IFTS) ${ }^{, 53}$ Full IFTS accreditation is: 'aimed at major PSI traders and trading funds. It is based on a full audit of information trading activities and is intended for bodies who wish to meet a very high standard of compliance with IFTS principles and the 'Re-use of Public Sector Information Regulations 2005' (SI 1515/2005) (PSI regulations). Full IFTS Accreditation ensures that re-users of PSI can be confident that they will be treated reasonably and fairly by PSI providers. Any public sector body may apply to become IFTS Accredited. However, all Crown bodies that have a full licensing delegation from the Controller of HMSO must 
become IFTS accredited'. To be recognised as accredited information 'fair trader', a public sector body must make a commitment to information fair trader principles, have the commitment independently verified and agree to investigate complaints when it is alleged that the commitment has not been met. ${ }^{54}$

This had been encouraged by the e-envoy's office that became the E-Government Unit that in turn became the Delivery and Transformation Group. The group is part of the Cabinet Office and has responsibility to ensure that IT supports the 'business transformation' of the government and thereby to secure 'better and more efficient public services'. It is clear that the intent is to create a much broader set of guidance that goes beyond any licensing arrangement. A review of the first two years of operation of the scheme reported in 2005. ${ }^{55}$ In support of its fair trader principles, OPSI itself published in 2007 its publication scheme, providing details of how to access its publications and the charges involved in respect of the different publication classes. ${ }^{56}$

\subsection{Re-organisation of PSI management in the wake of the PSI regulations}

In addition to its review of the knowledge economy, the government also consulted on the future role and scope of a 'repositioned' HMSO as a regulatory body. It began the process in October 2001 with a consultation paper $^{57}$ raising policy options on the future arrangements for the licensing of Crown copyright. The analysis of responses ${ }^{58}$ and outcome $^{59}$ of that exercise were published in 2002. This proposed transparent pricing policies indicated that unless HMSO won the consent of the information providers themselves, 'we do not believe that we will be able to achieve better dissemination and pricing'. ${ }^{60}$ On 16 May 2005, the OPSI commenced operations with HMSO operating within OPSI pursuing its core activities of the management of Crown copyright and database rights, publication of legislation and provision of official publishing guidance. ${ }^{61}$

More significant restructuring took place in late 2006 that will have an important impact on the future of UK information policy. This 'quiet revolution' affected institutions such as The National Archives (TNA), HMSO and The Stationery Office (TSO) as well as OPSI. OPSI was established in May 2005 when HMSO was effectively subsumed within OPSI. However, the formal office and titles of HMSO continued at that point including its responsibilities for the management of Crown copyright and the publication of legislation. OPSI was given responsibility for coordinating information policy standards on the re-use of PSI following UK implementation ${ }^{62}$ of the EU Directive on the re-use of PSI in July $2005 .^{63}$

What has actually happened is that OPSI became in 2006 the 'principal focal point for PSI in the UK' ${ }^{64}$ In October 2006, TNA and OPSI merged, with the former contributing its considerable expertise in information and records management. TNA maintains one of the largest national archives in the world, 'spanning 1,000 years of British history' and has led the way in the development of electronic records management to replace paper systems as well as advising the wider public sector on best practice in this area. OPSI's role will be to build on that expertise as 'regulator of PSIHs for their information trading activities'.

Operating then from within OPSI is HMSO. A clickable link from OPSI's main web page originally asked 'where has the HMSO website gone?' The answer given when the link opened was that OPSI had 'grown out of Her Majesty's Stationery Office (HMSO)'. While OPSI's role would be to regulate the re-use of PSI, HMSO would continue to exist 
and 'fulfill its core activities including responsibility for the publication of legislation and the management of Crown copyright'. In effect, says OPSI, it is the 're-branding of what was the HMSO website - HMSOnline'. ${ }^{65}$

The final element in this latest round of changes concerned TSO. TSO specialises in the 'creation, production and distribution of information in print, online and in electronic formats', and was privatised from HMSO in $1996 .{ }^{66}$ It claims to be the largest publisher in the UK by volume, publishing more than 15,000 titles per annum purchased by more than 350,000 customers. On 15 November 2006, TSO announced that it was being acquired by Williams Lea, a global provider of corporate information solutions, subject to satisfactory competition clearance from the authorities. The acquisition announcement reported that this: 'establishes Williams Lea in the rapidly expanding market of public sector document business process outsourcing, which is forecast to grow at $23.5 \%$ compound annual growth rate to $£ 1.3$ billion by 2008. Demand is being driven by a growing number of government departments, changes in regulation and legislation and the desire to increase efficiencies within the public sector as a whole'.

These substantial changes will inevitably impact upon PSI policy in the UK. It would seem that the uppermost in the government's mind is improved efficiency in sharing information services within the public sector and generating benefits from the re-use of PSI. However, the issue is not just about efficiencies and cost savings, but in placing appropriate information in the right form in the right place at the right time, so as to feed into policy development. The issue becomes even more important as governments begin to utilise spatial information for this purpose.

There is no doubt that development of a robust information policy for the management and distribution of PSI is a key element of wider government plans for its transformational government programme announced in November 2005. ${ }^{67}$ This established an agenda for improving government services enabled by technology to 'release efficiencies' across the public sector ${ }^{68}$ including better arrangements for data sharing, information management and information assurance. Also embedded within this programme and within OPSI's remit is the responsibility to set standards, deliver access, and encourage the re-use of PSI and share best practice. APPSI believes that the merger in October 2006 of TNA $^{69}$ with OPSI will, through the greater resources and reach of TNA, 'provide a far more effective platform from which OPSI can promote and regulate the exploitation of PSI'.

\subsection{Importance of UK PSI again highlighted in 2006}

The commercial exploitation of PSI was again raised in 2006 from the unexpected source of the Office of Fair Trading - the UK's consumer and competition authority - that had previously not entered the debate. The report, - the commercial use of public information (OFT study) ${ }^{70}$ recommended that important changes were needed to the operation of the market for PSI. With the improvements proposed, OFT believes that the sector could double in terms of the "value it contributes to the UK economy to a figure of $£ 1$ billion annually'. This could be achieved by the production of a 'wider range of competitively priced goods and services for consumers and the generation of wider-spread productivity improvements across the economy'.

The OFT study noted that public sector information holders (PSIHs) were frequently the only source of the basic information they held. Such 'unrefined information' could not be readily substituted from other data sources. Once the PSIH processed the unrefined 
information in some way - a function that could potentially be also performed within the private sector - the information became 'refined'. The report argued that, for the sector to succeed and do well, improvements were needed in the accessibility of unrefined information by businesses seeking to use it to 'provide products or services to the public'.

Among the common issues identified was the inadequate availability of unrefined information with many businesses reporting their inability to obtain the latter in a sufficiently unrefined form to be usable for their purposes or the offer of licensing terms that effectively resulted in the products and services envisaged not being financially viable.

The OFT study also assessed the response to the 'HM Treasury Cross-Cutting Review of the Knowledge Economy ${ }^{71}$ that reported in 2000, which had recognised the 'central importance' of PSI to the knowledge economy and its development. The review had reached many similar conclusions to the present study and it noted that some progress had been made in as a result of OPSI's establishment and APPSI. However, despite these developments, the OFT indicated that the steps so far taken had not been sufficient to address what needed to be done i.e., - 'making PSI available on fair, consistent and non-discriminatory terms, with transparent pricing and licensing, in a timely manner and with the establishment of a quick and easily accessible complaints procedure'.

The OFT study then went on to consider a number of possible ways forward to implement what is desired e.g., to require PSIHs to 'divest themselves of their refined information operations' or to charge nothing for the re-use of unrefined PSI. However, while an equal access policy might be sound in competition policy terms, some PSIHs were clearly dependent on the 'income from re-use to finance their operations'. It was also the case that some PSIHs handled their refined information operations in 'a fair and transparent manner' so the assumption that such an arrangement could never work was misplaced. Accordingly, the report sought a 'proportionate solution' that 'builds on the existing framework' to make it more effective. Among the recommendations that could be implemented without primary legislation was improved monitoring of the PSIHs that gain substantially from commercial exploitation of PSI, to ensure that key principles and guidance are followed. This should apply whether this was the main activity or only a by-product of the PSIH.

The OFT is also calling for more clarity about government policy on PSI, noting that the Re-use of Public Sector Information Regulations 2005, the Freedom of Information Act 2000, the Environmental Information Regulations 2004 and the Transformational Government Initiative ${ }^{72}$ all 'aim to make as much PSI available as widely and cheaply as possible'. However, financing of some PSIHs as trading fund operators - which imposed a duty to fulfill 'income generating targets' in the exploitation of PSI and also the WMI ${ }^{73}$ - both encouraged PSIHs to seek income from selling and licensing PSI. The study suggests the incentives behind the trading fund model and WMI could aggravate a situation where a monopoly supplier of PSI also engages in refined information activities, with insufficient scrutiny of their approach to equal access'. A consistent policy on PSI with corresponding clear guidance would 'help to ensure that the PSI sector can reach its full potential'. 


\subsection{Strategic review of PSI initiated by government in 2007}

Following a policy review on future challenges for the government, in February 2007, almost before the report could be digested, the then Minister for the Cabinet Office, Hilary Armstrong, asked Tom Steinberg, Director of MySociety - the charitable organisation involved in community website development - and Ed Mayo, Chief Executive of the National Consumer Council, to explore in yet another study 'the role of the government in helping to maximise the benefits for citizens' from the new patterns of online tools that 'allow people to use, re-use and create information in new ways'. The review $^{74}$ was conducted through a wide ranging literature review, three 'in depth' case studies $^{75}$ designed to illustrate the costs and benefits of more online PSI exchange and interviews with more than 60 stakeholders in central and local government, business and public bodies.

The report indicated that the government was now in a position to 'grasp the opportunities that are emerging in terms of the creation, consumption and re-use of information' although current policy and action had proved inadequate in achieving this goal. A strategy was recommended in which the government 'engages with user-generated sites in pursuit of common social and economic objectives'; improve the supply of government-held information to potential re-use innovators when they need it in a way that maximises the long-term benefits for all citizens; and protect the public interest by assisting excluded groups to take advantage of these information flows, while educating all citizens 'for a world of plentiful (and sometimes unreliable) information'.

Fifteen practical recommendations were forthcoming in line with this strategy designed to achieve the step change that was recommended. They were categorised into suggestions for 'exploring new opportunities', 'improving access to PSI', 'protecting the public interest' and 'follow through and next steps'. With the need for clear leadership to act upon the proposals, the report recommended that OPSI report to the Cabinet Sub-Committee on Electronic Service Delivery (PSX(E)) by December 2007 on 'departments' plans for implementing this report's recommendations and report again on progress and results by December 2008'.

The government response to the report appeared at first instance to be enthusiastic. Hilary Armstrong, who subsequently gave way to Prime Minister Gordon Brown's appointment of Ed Miliband to the Cabinet Office, noted that, in the eight years to 2006, household use of the internet in the UK had risen from $9 \%-57 \%$ - for example, 'a small group of mums can reach an audience of hundreds of thousands. They do not need a large organisation with an extensive IT support system or technological expertise. If 30,000 parents were meeting in a park or football stadium to share information and tips about parenting, the government would take notice'. ${ }^{76}$

The government's reply set out some elements of its thinking. Three main challenges were identified: 'engaging in partnership with user-led online communities, ensuring that it fully understands and responds appropriately to changes in the information market and advising civil servants on how best to participate in new media'. Somewhat unusually for the government, it admits that it is not going to be 'expert at this overnight - we need to experiment and learn in partnership', but it does express some disappointment that the reviewers did not recognise more fully 'the government's progress to date', accepting as it does the report's general findings that 'technological advances are increasing the value - especially the social and economic value - of information generated by the public sector'. 
On the issue of charging, licensing and regulation and how these issues might fit into future strategy, the government declared that it wanted more time. In particular, it said, it wanted to consider the 'Power of Information Review' alongside the OFT study on the commercial use of public information, ${ }^{77}$ just mentioned. For the time being, further work should take place on an 'evidence base' to test possible amendments to policy in relation to government bodies and the regulatory regime. However, the publishing climate was changing. The government noted with interest that individual innovators and social entrepreneurs could now 'create information goods and services that were once the preserve of large corporations'. This was an 'important new segment' of the knowledge economy and evidence of a 'healthy climate of innovation that demand for PSI is growing'.

Since the original response, the Central Office of Information (COI) has formed a strategic Delivery Coordination Group to implement the recommendations from the 'Power of Information Review' and other reviews so as to coordinate the activities of central government and avoid duplication. ${ }^{78}$

In what was almost its final act, prior to its replacement on 28 June 2007 by the Department of Business Enterprise and Regulatory Reform, the outgoing DTI published the government's response to the OFT study that same month. ${ }^{79}$ It welcomed the study as one that usefully built upon the 'HM Treasury's Cross-Cutting Review' of 2000 and the Cabinet Office 'Power of Information Review'. The government acknowledged the 'estimated economic benefits' highlighted in the OFT study, but at the same time had to consider the costs, thereby 'ensuring the ongoing financial provision of the information currently collected, the fiscal cost and the costs to the bodies affected by the OFT's recommendations'. It indicated that the likely scale of these costs remained 'unknown' and that more work would be needed to 'make sensible indicative assessments'.

Other key actions referred to in the OFT study were also taken up. Trading fund operators would now prepare an action plan 'setting out where they are now and how they propose to open access to their information, further using the principles for improving pricing and dissemination set out in the 'Knowledge Economy' report'. There would also be improved guidance for PSIHs and accountability through OFT's competition enforcement activities and a statement in the annual accounts as to compliance with cost allocation and charging principles. The government also declared that it was 'encouraged' that the IFTS already included a number of principles alluded to in the OFT study. It hoped that, as the scheme expanded, 'better practice will spread through the sector' including 'clear and fair licence terms' and complaints procedures that were 'fair, transparent and not punitive'. As far as other matters in the action plan were concerned, the response paper indicated that these could not be accepted at this time. In particular, further work was required by officials 'to consider the impact of changing data definitions and pricing policy, especially for trading funds, to ensure there are not adverse impacts on the ability to collect the information in the future and that the proposed benefit is sufficient to justify the fiscal cost'.

\subsection{Review of trading fund models for the provision of PSI?}

The further accumulation of the evidence base that the government called for before it could begin to contemplate decisions on future re-use strategy grew significantly in 2008. How information might be better exploited so as to improve its value and utility both to 
the public sector and the country at large was the focus of a major study, published in February 2008, by academics from Cambridge University. The group's remit was to examine the 'impact of adopting different models for the provision of PSI by trading funds', ${ }^{80}$ such as the Meteorological Office, Ordnance Survey (OS), the UK Hydrographic Office, the Land Registry, Companies House and the Driver Vehicle Licensing Agency. These were the six largest trading fund operators in terms of revenue generated. The study fulfills one of the recommendations in the OFT study ${ }^{81}$ and the 'Power of Information Review' ${ }^{82}$ that such work is required.

While the connection with information policy might at first sight appear obscure, there have for some time been calls for the government to review the effectiveness of its policy that requires a direct economic return on the sale of PSI. Whereas the Cambridge study reported that this charging mechanism for the supply of PSI was producing $£ 390$ million per annum, according to the latest figures available, an alternative scenario might be to examine the 'downstream returns' and other benefits to society that might be obtained if different models were considered. The study noted that 'the demand for digital data as with other information services is likely to be high and growing' and that 'the case for pricing no higher than marginal cost (which, for most digital data will be zero) on basic products is very strong'. The study also remarked that the case for 'hard budget constraints' designed to 'ensure efficient provision and induce innovative product development' in information services was weak when the public enterprise concerned was engaged in provision of a monopoly service without fear of competition. So, while a 'socially optimal policy' would leave the charging regime in most cases unchanged in respect of 'refined products' built on unrefined data where there was already good commercial competition, for the bulk of unrefined digital data, this should be freely available.

Such findings will be noted with interest by private sector information providers who have argued, along with the 'free our data' campaign ${ }^{83}$ that there are greater benefits to be obtained for the UK, both financially and for individual users, if the information market were more open. At present, as with the rest of the EU, the principles governing the re-use of PSI are regulated by EU Directive 2003/98/EC ${ }^{84}$ and implemented by domestic regulation ${ }^{85}$ that manages to preserve the present policy regime. The initial response of the government to the Cambridge report, as indicated by the HM Treasury in its Budget Report for $2008^{86}$, cautiously suggests that there is a need to look at PSI held by trading funds 'to distinguish more clearly what is required by the government for public tasks and to ensure that this information is made as widely available as possible for use in downstream markets'. In the meantime, however, it restates the position that the need for access to such data must be 'balanced with ensuring that customers pay a fair contribution to the cost of collecting this information in the long term'. If that is the eventual outcome of consideration of this issue within the planned spending review, then the status quo will of course have been substantially maintained.

\subsection{The review of EU Directive 2003/98/EC and the PSI regulations}

UK policy towards PSI has now of course been decanted into the broader environment of EU policy. Having progressed from the first tentative steps on the re-use of PSI in 1989, with non binding guidelines ${ }^{87}$ which aimed to 'strengthen the position of the private sector in the European information market and limiting the role of the public sector bodies to the supply of raw data', this progressed nearly a decade later in 1998 to a Green 
Paper on PSI ${ }^{88}$ Subsequently, a proposal for a directive was published ultimately leading to the PSI Directive in $2003 .^{89}$ The UK Government had prepared well for the implementation of the directive having secured its economic position on policy towards Crown copyright, trading fund operators as holders of PSI and acceptance of its schemes for identifying and cataloguing available data for access and re-use. ${ }^{90}$

Progress in implementing the directive in the UK was reviewed in 2007 by OPSI. (Re-use report). ${ }^{91}$ This analysis ran side by side with the other studies previously mentioned and the organisational changes within OPSI - all part of a process that in part were designed to better operate and manage the 2005 PSI Regulations. The effect of these regulations is summarised as follows:

'The main aim of the PSI regulations is to maximise the re-use of PSI and to stimulate the economy. Within the spirit of the PSI regulations, a PSIH is expected to encourage the re-use of its information. Although the PSI regulations impose no obligation on a PSIH to allow the re-use use of its information, the purpose of the regulations is to establish a framework that provides for the effective re-use of PSI. If re-use is allowed, a PSIH should:

- Publish a list of the main documents available for re-use.

- Respond promptly to requests for re-use.

- Put in place copyright and licensing arrangements.

- Ensure that any conditions on re-use do not unnecessarily restrict re-use or competition.

- Ensure that there is no discrimination between applicants. If a public sector body wishes to re-use a document for activities which fall outside its public task, the same conditions shall apply to that re-use as would apply to re-use by any other applicant for comparable purposes.

- Discourage exclusive arrangements.

- Set up appropriate internal complaints procedures. There is also the option of asking OPSI to investigate the PSIH's actions and this should be made clear in the internal procedures, ${ }^{92}$

The Re-use report concluded that the UK's PSI assets were 'extremely valuable yet often under-utilised' and that policy and action taken by OPSI and others now needed to be placed 'within the wider information policy context'. Among the further actions proposed to 'ensure that UK grasps the opportunities to maximise the potential of PSI' were a new look at the PSI regulations in the light of the EU review planned for $2008^{93}$ and clarification of the distinction between the production of PSI in the performance of a public task and its re-use within the public sector. The Re-use report noted that in the interests of fairness, it was not always apparent 'whether an activity carried out by a public sector organisation' was a 'public task or a re-use activity'. It also declared that OPSI would 'clarify the UK approach' towards the use of third party copyright material in PSI in the wake of the outcome of a complaint (see below) in 2006 against the national mapping agency OS concerning the licensing of its product AddressPoint to a third party and OS' subsequent use of its product. ${ }^{94}$ 
In addition, OPSI has undertaken to clarify the distinction between access and the re-use of PSI. This distinction can cause confusion and is important in the relationship between the Information Commissioner's responsibilities under the Freedom of Information Act, the Environmental Information Regulations ${ }^{95}$ and the Data Protection Act 1998 which focuses on 'access' issues; and the responsibilities of OPSI under the PSI regulations, which relate to the re-use of information once access has been granted or where it is already accessible. The issue can be relevant in determining who should handle complaints.

Another matter that OPSI has resolved to look into is the effect of the absence in both the PSI directive and regulations of an obligation on the part of the PSIH to facilitate the re-use of documents. The Re-use report finds evidence of a lack of awareness of the re-use compliance rules among some PSIHs despite the fact that the PSI regulations forbid discrimination in any conditions imposed and similar treatment where the public sector body has used the information itself as part of a public task. OPSI has undertaken to look at better ways of ensuring greater compliance with the rules. ${ }^{96}$

OPSI further commits to enhance awareness of its 'click-use' licence launched in $2001^{97}$ in consultation with private sector re-users for a 'wide range of PSI'. The Re-use report notes that more than 13,000 such licences have been taken out since it started, permitting many forms of re-use 'from research by private individuals to commercial publishing by multi-national companies', but subject of course in some cases to payment of royalties. OPSI also wants to extend the IFTS $^{98}$ to all PSIHs generating more than $£ 100,000$ income from the licensing of its material and to 'continue working with other parts of the government to ensure a unified and integrated approach to managing information assets'. It also undertakes to review complaints procedures in consultation with APPSI in the light of the first two years' experience of the scheme.

What is evident here is an attempt within OPSI to fine tune existing arrangements so as to make them more effective and adhered to. Whether this will lead to any fundamental relaxations of policy towards access depends on the extent to which a good economic case can be made and proven for enhanced access and re-use rights. It is clear that APPSI, in its role as an NDPB, has commented on a wide range of policy issues at the heart of the PSI agenda. However, the question remains to what extent the government is prepared to engage with APPSI at the highest level. In its 2006 Annual Report, it comments that:
"Most APPSI members have been disappointed in the past year with our inability to stimulate and secure ministerial interest in PSI at the Cabinet Office. It will be recalled that many of our recommendations in last year's report required ministerial engagement. Perhaps because APPSI did not make its case forcefully enough or perhaps because Cabinet Office Ministers had other more pressing and mainstream demands on their time, the reality is that APPSI has not met with any Minister over the past 18 months, despite attempts to set up meetings. Still, less have Ministers actively pursued any PSI initiatives. Were it not for our relocation to the Department of Constitutional Affairs (DCA), APPSI would focus very much more on this issue in this report. However, given we have been relocated and the interests of APPSI seem so well aligned with the DCA, our approach here is to be positive and look forward to develop a healthy relationship with DCA and its Ministers."99

While later APPSI reports are not yet available, it is quite evident that some progress has been made in gaining the government's attention to aspects of information policy at least in the context of recent administrative blunders that directly led to the loss of significant 
amounts of personal data by the public sector. Whether this extends to Senior Ministers and to the broader issues of access, re-use and charging arrangements within the scope of information policy remains to be seen. With the EU planning a review of the PSI Directive in 2008, this may raise information policy to a higher level on the government's political agenda. Nevertheless, APPSI remains an important independent voice on information policy able to draw the public and the government's attention to the broader issues that no single department or group could otherwise achieve without access to the kind of impartial expertise that is available to APPSI.

\subsection{PSI regulations on re-use tested in court}

An interesting illustration of how the present policy is working in practice can be seen from a case in 2007 in the Chancery Division involving HMSO, OS and an alleged unauthorised user of its mapping data. ${ }^{100}$ The court ruled that Crown copyright infringement took place when the defendant Green Amps Ltd. employed a university student to access mapping data which should have been available to the student only for educational purposes. The defendant's business lay in the provision of wind turbines in the UK for the generation of renewable energy. OS provided map data to provide a networked database service known as EDINA to members of the UK tertiary education and research community. One of the resources offered was called DIGIMAP which allowed access to OS digital maps (Digimaps), the use of which was licensed as part of the service. One of its licensees in 2005 was the University of Southampton to whom the student was affiliated. In the Easter and summer vacations of 2005, the defendant employed the student who continued to have access to the data in question. The student had further admitted using a fellow student's password and log in details having failed to understand the subscription process for accessing the data.

The student used EDINA both for the purposes of his degree course and to assist him in the tasks which he was asked to perform for the defendant. As a result, digital maps for the whole of Great Britain in three formats were downloaded without permission in circumstances where the annual licence fees for a single computer terminal for these products would have exceeded $£ 16,000$. In order to download the DIGIMAP product, the defendant would have observed on the screen the claimant's copyright terms and conditions which notified the user that the OS data within DIGIMAP was subject to Crown copyright. The defendant would also have had to click on an icon agreeing to the terms and conditions which made it clear (inter alia) that access to the DIGIMAP service was restricted to further and higher educational institutions and for education purposes, defined as 'education, teaching, distance learning, private study and/research'.

In the court's view, it was clear that the defendant's acts were not licensed and there was no dispute that, unless justified by provisions of the CDPA 1988 or other provisions of the law, the defendants had infringed copyright. The defence case was mainly conducted on interpretation of the PSI regulations and the fair use defence set out in Section 29 of the CDPA 1988. Paragraph 15 of the regulations, implements the PSI Directive and permits a public sector body to charge for the re-use of PSI and so far as reasonably practicable, to establish standard charges for this purpose. The defendant argued that the regulation permitted the claimants to charge only the cost of reproducing the maps plus a reasonable return on the amount expended in doing this. The basis of this submission was said to be the view expressed in the OPSI report on its investigation of a 
complaint by Intelligent Addressing Limited that OS' activity of maps supply fell within its 'public task' with the result that the regulations applied to it. ${ }^{101}$

The court remarked that OS' 'public task' was 'clearly a difficult one'. However, it was clear from the PSI Directive and from the regulations that the claimants were 'entitled to base their charges on all the expenditure incurred in the collection of information, mapping and other activities carried out in order to provide the end product, together with a reasonable return on that expenditure, which represents their investment'. The court emphasised the point that even if a public sector body sought to levy charges in excess of permissible charges, this would not give a member of the public the right to use the information free of charge. The regulations provided for an internal complaints procedure and when this was exhausted for a complaint to the OPSI, then finally to review by an advisory panel.

On the issue of fair dealing, the defendant had argued that its purpose was to develop a mapping tool which was ultimately to be used in planning applications for wind turbines and was 'essential in correlating the different mapping layers incorporated' in the environmental statements which formed part of such applications. In its view, the mapping tool had a research and development status within the terms of their use and once it came to be used commercially, it became a function of the quasi judicial planning process and therefore exempt from copyright infringement under Section 45(1) of CDPA 1988. The court rejected this on the grounds that the fair use exemption in Section 29 required that what would otherwise be an act of infringement must be 'for the purposes of research' and that the research should be 'for a non-commercial purpose' to avoid liability. The second of these requirements had plainly not been satisfied since the defendant was a commercial company in which even if its initial use of the mapping data had been for research, the end product of that research was for commercial purposes. The objective standard of fair dealing, namely whether a fair minded and honest person would have dealt with the copyright work in the manner in which the defendant did, produced a clear answer.

Among the main factors, said the court, to be taken into account were the degree to which the infringement involved competition with the exploitation of the copyright work by the owner, and the extent and importance of the copying. In the court's view, 'by both of these criteria, the defendant's infringement comes very high on the scale. Add to this, the covert manner in which the information was downloaded'. Those that did it must have known it was illegitimate. The court went on to dismiss all other arguments in the amended defence and concluded that the defendant had no arguable defence to the claim. Accordingly, judgment was given in default of defence.

\subsection{Evaluation of the cost recovery regime - the case of OS}

How the pricing approach for access to PSI should be judged is entirely dependent upon which economic model for exploitation of PSI is adopted. Arguments could be made that a more relaxed regime would stimulate the market for new products and services. On the other hand, so long as the funding mechanisms continue that bind trading fund operators to seek a return on their PSI holdings, issues like this will continue to arise and be litigated. It remains a complex issue. The 'free our data campaign', on the other hand, argues that the policy inhibits innovation and penalises the taxpayer: 


\begin{abstract}
“On March 9, 2006, the Guardian's [Newspaper] Technology supplement carried an article called 'Give us back our crown jewels'. The argument is simple: government-funded and approved agencies such as the OS and UK Hydrographic Office and Highways Agency are government-owned agencies; they collect data on our behalf. So why can't we get at that data as easily as we can Google Maps or the Xtides program? Even though OS and the UK Hydrographic Office are designated as trading funds (which means that they operate as self-contained commercial entities receiving no direct tax funding), substantial parts of their income - up to $50 \%$ in the case of OS - comes from the public sector; meaning, in effect, they are part-paid by taxes. Yet, they charge for that data, with onerous copyright restrictions that prevent the re-use of the data that restricts innovation and artificially restricts the number and variety of organisations that can offer services based on that most useful data which our taxes have helped to collect. Making that data available for use for free - rather as commercial companies such as Amazon and Google do with their catalogue and maps data - would vastly expand the range of services available. It cannot make any sense that Google, a US organisation, is presently more popular with people aiming to create new map applications."102
\end{abstract}

OS, however, as one of the trading funds most heavily criticised, argues that the issues are more complex than the campaigners would suggest. ${ }^{103}$ OS comments that maintenance of its map data is a vital issue with some 5,000 changes per working day to its large scale map data for Great Britain. OS suggests in its defence that there is no such thing as 'free data' since the collection, maintenance and distribution of its data cost OS $£ 105$ million in 2004-2005 being the most up to date figure available. OS argues that it is very unlikely that the HM Treasury would agree to fund such work and that 'no political will from any of the mainstream political parties to return to funding national geographic data collection' was discernable.

With regard to innovation and the argument that its present policies stifle new ideas, OS argues that it has more than 500 commercial partners with which it has been working over the past five years to 2006. It points to US experience which the campaign argues provides a better model, since PSI is made more freely available and reminds the campaign that US Central Government mapping is of variable quality with much of the data remaining unrevised for 30 years or more. Moreover, the private sector in the USA has 'no obligation to map either to consistent national standards, consistent currency or even to provide complete coverage'. OS concludes that the present model of funding and licensing its products has enabled the organisation to retain not only its position as a 'leading edge, technologically driven organisation and a world leader in the national mapping agency sector' maintaining one of the world's largest geospatial databases, but also facilitated its membership of OPSI's IFTS thereby delivering substantial amounts of freely accessible small scale map data online to the general public as well as a free OS explorer map to every 11 year old child in Britain!

Perhaps partly as a response to the high profile of the PSI issue as a result of the campaign and the particular concerns raised about OS, it was not surprising that at some stage, Parliament would decide to investigate. This took place following the decision in 2008 of the House of Commons Communities and Local Government Select Committee to review the alleged confusion between OS' public service and commercial roles in relation to PSI. ${ }^{104}$ Whereas OS argued that a clear distinction between the two roles was impossible, the Select Committee wanted to find out whether the regulatory frameworks in place to mitigate the difficulties arising from the dominant position of OS in the field 
of geographic information provision were, as had been alleged, 'difficult to use and ineffective'.

The Select Committee discovered that OS did in fact cost the tax payer nothing as it returned an annual profit to the HM Treasury. However, the fact that it is required to fund both its public and commercial activities from its own revenues did make it difficult to determine where its public duty ended and its competition in the market commenced. Whereas the committee noted that most of the funding to support OS came from licensing the re-use of its information, international experience suggested that 'any diminution in its funding levels could affect the quality of the information it provides its customers'. However, the committee was critical of some licensing practices particularly clauses with competitors that restricted their rights to compete. No such conditions should be included in such licences in the future as had been found in the Intelligent Addressing complaint. ${ }^{105}$ In general, OS' licences were 'too complex and inflexible' and needed to be much more transparent. Licences needed to fit the needs of customers, while protecting OS' intellectual property.

The committee was also concerned over the extent to which the PSI regulations applied to OS activities and the failure of the arbitration process to overcome these hurdles. ${ }^{106}$ The committee believed that products to which OS had added value and which were being marketed commercially, should be part of its private portfolio. However, the base information in OS' hands, in its capacity as the national mapping agency, should be 'as easily and widely available as possible, allowing for cost recovery'. It was possible that the regulations, as currently drafted, might be 'inadequate' in ensuring that base information was easily accessible and it called upon the government to remedy any deficiencies that existed.

The committee also welcomed the creation of a Geographic Information Panel for geo-spatial PSI, similar in some respects to APPSI's role in the wider domain, since its main role was to give 'high-level advice to (Office of Deputy Prime Minister) ${ }^{107}$ Ministers on geographic information issues of national importance for the UK'. This included identifying 'the key medium to long-term geographic information issues; advising the government through regular short reports to Ministers; encouraging more effective, extensive and systematic use of geographic information, led by the example of government departments and other public bodies where appropriate; facilitating a co-coordinated position on potential legislation, both national and international, that might impact on the geographic information market and promoting a coherent approach to the management of geographic information in the UK'. Again, similar to APPSI, the panel is advisory only and has no regulatory role.

Clearly, the committee feels that there are issues about the working of the PSI regulations that need to be clarified such as the exact nature of what is a 'public task' in the midst of departmental or trading fund commercial activity where issues about compliance and non-discrimination are not altogether clear. Certainly, in the context of spatial data, more work needs to be done among all those involved to overcome these concerns particularly as implementation of the Inspire Directive establishing an EU infrastructure for spatial information must be in place by 15 May 2009. ${ }^{108}$ 


\section{Conclusions}

In summing up the situation, it is clear that serious work continues to assess the impact of different policies towards the ownership and licensing of PSI. The perception of the government in the past has been of a public sector that sees PSI as a government property that it is fully entitled and indeed under a duty to the taxpayer to regulate, licence and sell. Now, we have the transformation agenda where additional pressures exist to use information to achieve results, reduce costs and particularly to engage the public in a form that satisfies both the business case for government efficiency and legal requirements such as adherence to freedom of information rules.

The debate will continue with the information industry however, as to the merits and demerits of a policy that still requires compliance with the regulatory bureaucracy for the exploitation and use of PSI. While the government has recognised the need for much more flexible arrangements in the digital environment, difficulties still remain for example in overcoming the confused position that operated within departments and trading funds over pricing, access and identification of their information assets. The private sector will of course always want the policy to go further towards the diversity model of the USA that imposes virtually no restrictions on the use and re-publication of official information. In pure economic terms, it is difficult to assess the benefits of the US approach as statistics are hard to produce. Up to now, the HM Treasury has formulated its own model which lays down that departments and trading fund operators must, as far as possible, operate financially in a self-sufficient way. PSI, then, is a commodity that can be sold or licensed for a fee which will contribute to public sector funding. Perhaps, the way forward might be to look closely at the IAR and to consider whether all categories of data must be treated alike. It may well be that while, for a variety of reasons, some specialist categories of material must be retained within a commercial licensing regime, other data can be released without significant economic consequences. Whereas geospatial digital map and meteorological data may be extremely valuable to the trading funds that produce them, there may be alternatives to the present funding models under which such data are exploited. But there will be substantial volumes of other official information for which no such argument applies in their present form, but only when value is added.

The issue of access to PSI and the commercial interests in adding value for the purposes of its exploitation is one that will, however, continue to bear down on the government policymakers as they continue to set access and pricing structures. Whereas, in the past, one might have been forgiven for drawing the assumption that most of the data was likely to be in written form, today, there is the added dimension of spatial data. In 2007, the EU passed a directive 2007/2/EC ${ }^{109}$ designed to establish a framework for a spatial data infrastructure in Europe. The latter is a data which includes a reference to a two or three dimensional position in space, otherwise known as geographic or geospatial information and has many important potential applications both within and outside the public sector. The intellectual property rights to such data already belong to trading funds such as OS and this will not change for the moment. However, the rapid growth of online services linked to such products as Google Earth is indicative of the importance of establishing European ground-rules for the creation of a framework for such data that will maximise their utility and value in a wide range of public sector activities. Implementation of the provisions of the directive must be completed by May 2009 and 
while existing intellectual property rights remain unaffected by the directive, it would seem that pressure on governments such as the UK to relax pricing policies or other restrictions on access and exploitation of spatial data can only increase.

The UK Government has always maintained a desire that some forms of PSI should generate a direct economic return. While other operating models have been applied elsewhere, the UK has, to a large extent, retained its present policies, but subject to some relaxations where the social or economic benefits of access and use have outweighed the demands for cost recovery. However, it is clear that at present, the policy is under sharper scrutiny than ever before, since the pool of research data is now growing that will sharpen the debate on the way forward. It does seem then that evidence as to the impact of alternative approaches to present pricing policy is at least mounting, although the upheaval facing the major trading fund operators of any significant changes should not be under-estimated. New fiscal arrangements would have to be found by the central government to fund these service providers. Given the pressure on the UK position implied by EU access policy, the government is going to have to build a compelling case if it is to retain present structures completely unaltered and intact.

Finally, it should be noted that a policy that grants the private sector access to PSI may not avoid controversy either. Often it is not the case of the public sector simply handing over PSI to the commercial provider, but some sort of collaboration such as that which is currently taking place with the collection and online provision of Parliamentary papers via ProQuest - a commercial information provider in association with the education and research support body - the Joint Information Systems Committee (JISC). Issues such as public access rights and charges for access can surface even among this type of initiative. It is easy to forget then that the ultimate goal of PSI should be to use it so as to produce both better government and a more informed general public and business user. Within that objective lies the conundrum of how to achieve the best economic return for PSI as well as widespread access that may or may not involve up front charging when compared to the downstream results that may be gained from cascading information into the public domain through a variety of channels and forms. It remains to be seen whether the government has struck the right balance with its present policy or whether further change is simply inevitable.

\section{Notes}

1 Prerogative powers, which had extended to statutes, were abolished by the Copyright Designs and Patents Act 1988 s.164(4).

2 Cmnd. 6732, 1977.

3 Copyright Designs and Patents Act 1988, s.163(1).

4 Ibid., s.165(1). It was thought more appropriate for control of such publications to be with the House in question rather than with HMSO.

5 See ante.

6 For discussion of this, see (1998) Crown Copyright in the Information Age, Cm.3819, Ch. 2, available at http://www.opsi.gov.uk/advice/crown-copyright/crown-copyright-in-theinformation-age.pdf.

7 Ibid., p.1.

8 Defence - Evaluation and Research Agency - £8.09m; UK Hydrographic Office - £37.41m and Meteorological Office - £21.75m; HM Land Registry - £22m; Office of National Statistics - £6.6m; OS - £69m and Trade and Industry - £12.23m. 
9 Op. cit., note 6, Annex B.

10 Op. cit., note 6, para. 2.37.

11 HM Treasury (2000) 'Cost cutting review of the knowledge economy review of government information, December.

12 Trading funds were introduced by the Government Trading Funds Act 1973 (as amended by the Government Trading Act 1990). Essentially, a trading fund 'is a means of financing trading activities undertaken by the government that would previously have been financed by the annual appropriations from the Parliament, in the form of vote funding. A trading fund permits the establishment of a self-accounting unit that, while remaining under the control and management of Ministers (and accountable to Parliament through Ministers), has greater freedom to manage its financial affairs'. Source: Department of Transport (2003) 'Vehicle inspectorate traffic area network establishment of a trading fund - consultation document', January, paras. 18-19.

13 See Ministerial Statement of 9 February 1996, available at http://www.hmso.gov.uk/duchy.htm.

14 DTI (1990) Government-Held Tradeable Information - Guidelines for Government Departments in Dealing with the Private Sector, 2nd ed.

15 Op. cit., note 6.

16 See http://www.opsi.gov.uk/advice/crown-copyright/copyright-guidance/reproduction-oflegislation.

17 Dear Publisher Letter - Reproduction of Crown Copyright Material, dated 21 February 1997, para. 4.2.

18 The value-added requirement does not extend, however, to copying undertaken by libraries for academic use, or for research or private study.

19 Dear Publisher Letter - Reproduction of Parliamentary Copyright Material, dated 21 February 1997, para. 5.3 and Annexes. See now http://www.opsi.gov.uk/officialpublications/index.htm.

20 Paperwork Reduction Act 1995, 44 U.S.C., Ch. 35, Pub. Law 104-13, 104th Congress - 1st Sess., 109 Stat 163 (22 May 1995) Sec. 3506(d)(4).

21 H.C. Hansard, 6 November 1996, Col. 510.

22 Ibid.

23 Op. cit., note 6.

24 Ibid., p.2.

25 (1999) The Future Management of Crown Copyright, Cm 4300, available at http://www.opsi.gov.uk/advice/crown-copyright/future-management-of-crown-copyright.pdf.

26 Ibid., para. 2.6.

27 Annex $A$ to the White Paper lists a total of 70 responses to the Consultation Document plus a further five from authors requesting confidentiality.

28 Ibid., para. 3.1.

29 Ibid., para. 4.2.

30 Ibid., para. 5.1. In this sense, the government saw Crown copyright as 'a brand or kitemark of quality indicating the status and authority of much of the material produced'.

31 Ibid., para. 7.9 .

32 Ibid.

33 Ibid., paras. 9.8-9.12.

34 HM Treasury (2002) HM Treasury - Selling into Wider Markets - A Policy Note for Public Bodies, (revision to 1998 Treasury Guidance), p.1, available at http://www.hm-treasury.gov.uk/media/0/D/New_WM_Guidance.pdf. 
35 Members include the Controller of HMSO and other HMSO personnel, representatives of the information industry and of relevant organisations.

36 The CCUG was initiated in 1999.

37 See http://www.appsi.gov.uk/.

38 The IAR is accessible through the Inforoute website which is to be the gateway to information held by the UK Government. See http://www.opsi.gov.uk/iar/index.htm.

39 From the website of the Department of Innovation, Universities and Skills, see http://www.dius.gov.uk/foi/asset_register.html.

40 HMSO (2000) Guidelines for the Preparation of IAR Records, January. See further http://www.dius.gov.uk/foi/asset_register.html.

41 This was carried out by Sir Richard Wilson through whom the PIU reports to the Prime Minister.

42 The PIU was merged with the PM's Forward Strategy Unit and parts of the Centre for Management and Policy Studies in 2002.

43 HM Treasury (2003) Selling Government Services into Wider Markets - Policy and Guidance Note, Enterprise and Growth Unit, available at http://www.govopps.co.uk/guidance_db_files/guidances/Guidance04_03.pdf.

44 National Audit Office (2007) Government on the Internet: Progress in Delivering Information and Services Online, HC 529 Session 2006-07, 13 July, available at http://www.nao.org.uk/publications/nao_reports/06-07/0607529.pdf.

45 See http://www.hmtreasury.gov.uk/DOCUMENTS/PUBLIC_PRIVATE_PARTNERSHIPS/ ppp_index.cfm.

46 E-commerce@its.best.uk - A Performance and Innovation Unit Report, Cabinet Office. See http://www.ictparliament.org/CDTunisi/ict_compendium/paesi/uk/uk28.pdf.

47 Op. cit., para. 11.22.

48 Op. cit., note 11 ante.

49 Op. cit., note 6 ante.

50 Ibid., paras. 11.21-22. The government will say that such material must be accurately reproduced and not be misleading. It should also correctly acknowledge the source and status of the material.

51 The waiver extends to 'material of a legislative or consultative nature, where it is in the government's interest to encourage unrestricted use' (White Paper, para. 5.1). Examples include inter alia: legislation, government press notices and forms, ministerial speeches and articles and documents featured on official departmental websites.

52 For example, the White Paper indicates a licensing waiver for government press notices, but has issued a Guidance Note in respect of their reproduction and use. See http://www.opsi.gov.uk/advice/crown-copyright/copyright-guidance/reproduction-ofgovernment-press-notices.htm.

53 The Information Fair Trader Scheme 'sets and assesses standards for public sector bodies. It requires them to encourage the re-use of information and reach a standard of fairness and transparency'.

54 OPSI website: http://www.opsi.gov.uk/ifts/full-ifts.htm.

55 Cabinet Office, HMSO (2005) Information Fair Trader Scheme - The First Two Years, January, available at http://www.opsi.gov.uk/ifts/first-two-years-report.pdf.

56 See also Procedures for Investigating Complaints Arising Under the Re-use of Public Sector Information Regulations 2005, available at http://www.opsi.gov.uk/advice/psiregulations/ advice-and-guidance/psi-complaints-procedure.doc.

57 HMSO (2001) Licensing of Crown Copyright - HMSO Regulatory Framework, October, available at http://www.opsi.gov.uk/advice/crown-copyright/crown-copyright-licensingconsultation-outcome.pdf. 
58 HMSO (2002) Consultation on a Regulatory Framework for Crown Copyright - Analysis of Responses, available at http://www.opsi.gov.uk/advice/crown-copyright/licensing-consultation.htm.

59 Ibid.

60 Ibid., para. 5.

61 Saxby, S. (2005) 'Crown copyright regulation in the UK - is the debate still alive?', IJLIT, Vol. 13, p.299.

62 The Re-use of Public Sector Information Regulations 2005, SI 2005 No. 1515, available at http://www.opsi.gov.uk/si/si2005/20051515.htm.

63 Directive 2003/98/EC of the European Parliament and of the Council on the re-use of public sector information (the Directive) (O.J. No. L 345, 31.12.2003, p.90). See http://ec.europa.eu/information_society/policy/psi/docs/pdfs/directive/psi_directive_en.pdf.

64 See further http://www.opsi.gov.uk.

65 The only manifestation of HMSOnline was at: http://www.hmso.gov.uk/legislation/uk.htm (last updated in June 2004). See now http://www.opsi.gov.uk/advice/crowncopyright/copyright-guidance/index.htm.

66 See http://www.tso.co.uk.

67 Cabinet Office (2005) Transformational Government Enabled by Technology Cm6683, November, available at http://www.cio.gov.uk/documents/pdf/transgov/transgov-strategy.pdf.

68 Cabinet Office (2006) Transformational Government Implementation Plan, March, p.14, available at http://www.cio.gov.uk/transformational_government/implplan/.

69 The National Archives (http://www.nationalarchives.gov.uk/) describes itself as being 'at the heart of information policy - setting standards and supporting innovation in information and records management across the UK and providing a practical framework of the best practice for opening up and encouraging the re-use of public sector information'.

70 Office of Fair Trading (2006) The Commercial Use of Public Information (CUPI), December, OFT861. See The Commercial use of Public Information (CUPI), OFT861.

71 Op. cit., note 11 ante.

72 See further The Cabinet Office (2007) Transformational Government - Enabled by Technology - Annual Report 2006, January, Cm 6970, available at http://www.cio.gov.uk/documents/annual_report2006/trans_gov2006.pdf.

73 The Wider Markets Initiative was established by the HM Treasury in 1998 to encourage the more intensive use of public assets including intellectual property. See further Comptroller and Auditor General (2006) The Wider Markets Initiative, 27 January HC 799,

Session 2005-2006, available at http://www.partnershipsuk.org.uk/uploads/documents/pending/NAO_WMI_Jan_2006.pdf.

74 Mayo, E. and Steinberg, T. (2007) The Power of Information: An Independent Review, June, available at http://www.opsi.gov.uk/advice/poi/power-of-information-review.pdf.

75 The topics were: the benefits of health communities; the impacts of publishing restaurant food safety 'scores' and options for an online income tax self-assessment advice facility.

76 Mayo, E. and Steinberg, T. (2007) The Government's Response to the Power of Information: an Independent Review, Cm 7157 (Cabinet Office, June 2007), available at http://www.opsi.gov.uk/advice/poi/poir-government-response.pdf.

77 Op. cit., note 70 ante.

78 See Interim Progress Report on Implementing the Government's Response to the Power of Information Review (Cm7157). These include the Government Communications Group Social Media Review (http://www.publictechnology.net/print.php?sid=14994) and the National Audit Office (NAO) report (2007) Government on the Internet: Progress in Delivering Information and Services Online, 13, July, HC 529, Session 2006-07, available at http://www.governmentontheweb.org/downloads/report_2007/Government_On_The_Internet_ Full-Report.pdf. The latest progress report is: House of Commons Committee of Public 
Accounts (2008) Government on the Internet: Progress in Delivering Information and Services Online - Sixteenth Report of Session 2007-08, 29 April, HC 143, available at http://www.publications.parliament.uk/pa/cm200708/cmselect/cmpubacc/143/143.pdf.

79 DTI (2007) The Commercial Use of Public Information (CUPI) - The Government Response to the Office of Fair Trading Study, June, available at http://www.berr.gov.uk/files/file39966.pdf.

80 Newbery, D., Bently, L. and Pollock, R. (2008) Models of Public Sector Information Provision via Trading Funds, Study commissioned jointly by the Department for Business, Enterprise and Regulatory Reform (BERR) and HM Treasury, 26 February, available at http://www.berr.gov.uk/files/file45136.pdf.

81 Op. cit., note 70 ante.

82 Op. cit., note 74 ante.

83 See further http://www.freeourdata.org.uk/.

84 Op. cit., note 63 ante.

85 Op. cit., note 62 ante.

86 HM Treasury (2008) Budget 2008 - Stability and Opportunity: Building a Strong Sustainable Future HC388, March, para. 3.49, available at http://www.hm-treasury.gov.uk/media/9/9/bud08_completereport.pdf.

87 Guidelines for enhancing synergy between public and private sectors (non binding) 1989. See further http://www.egovbarriers.org/?view=Subject\&subject=psi.

88 European Commission COM (1998) Public Sector Information: A Key Resource for Europe, p.585, available at http://ftp.cordis.lu/pub/econtent/docs/gp_en.pdf.

89 Op. cit., note 80 ante.

90 For the time being, implementation of the PSI Directive is being coordinated from a portal ePSIplus (http://www.epsiplus.net/) - described as 'a practical 'one-stop shop' for key information on PSI re-use across Europe'. This support mechanism will operate in the build up to the expected review of the PSI Directive in 2008.

91 OPSI (2007) The United Kingdom Implementation of the European Directive on the Re-use of Public Sector Information, July, available at http://www.opsi.gov.uk/advice/psi-regulations/uk-implementation-first-years.pdf.

92 OPSI (2006) Office of Public Sector Information Report on its Investigation of a Complaint (SO42/8/4): Intelligent Addressing and Ordnance Survey, July, available at http://www.opsi.gov.uk/advice/psi-regulations/complaints/SO-42-8-4.pdf.

93 See further http://www.epsiplus.net/.

94 Ibid., AddressPoint is a dataset that 'defines and locates residential, business and public postal addresses in Great Britain. It is created by matching information from OS digital map databases with addresses recorded in the Royal Mail Postal Address File (PAF)'. See http://www.ordnancesurvey.co.uk/oswebsite/products/addresspoint/.

95 Op. cit., note 62 ante.

96 This applies particularly to the 'highly competitive' market in property searches currently undertaken by both public and private sector bodies where the report suggests that 'many local authorities do not apply the same terms for their own re-use as they do to others'.

97 See further http://www.opsi.gov.uk/click-use/index.htm.

98 http://www.opsi.gov.uk/ifts/index.htm.

99 APPSI (2006) Realising the Value of Public Sector Information - Annual Report 2006. Since 9 May 2007, the responsibilities of the DCA have transferred to the new Ministry of Justice. See http://www.justice.gov.uk/.

100 HMSO and Anor. v. Green Amps Ltd. (2007) EWHC 2755 (Ch), 05 November.

101 Op. cit., note 92 ante. See http://www.agi.org.uk/pooled/articles/BF_NEWSART/view.asp? Q=BF_NEWSART_211067. On this occasion, OPSI found that the terms of the OS licence 
'unnecessarily restricted the way in which (the original data) could be re-used and unnecessarily restricted competition'.

102 See http://www.freeourdata.org.uk/.

103 Free Our Data: Articles: the Ordnance Survey official response at: http://www.freeourdata.org.uk/ordnancereply.php.

104 The Stationery Office (2008) Ordnance Survey House of Commons Communities and Local Government Committee Fifth Report of Session 2007-08 HC 268, 21 January, Incorporating HC 1039, Session 2006-07.

105 Op. cit., note 101 ante. See

http://www.publications.parliament.uk/pa/cm200708/cmselect/cmcomloc/268/268.pdf.

106 Op. cit., note 92 ante.

107 Note that the Department for Communities and Local Government, formed in May 2006, is the successor department to the Office of the Deputy Prime Minister (ODPM). It describes itself as 'an expanded department with a powerful new remit to promote building more and better homes, reducing homelessness, improving local public services, regenerating areas to create more jobs, working to produce a sustainable environment and tackling anti-social behaviour and extremism'.

108 This European directive will 'require governments to make geographical data available more easily, in order to underpin common policies to protect the environment. The idea is to ensure that environmental data is collected to the same standards and scales across Europe and is freely available to all'. See e.g.,

http://www.guardian.co.uk/technology/2006/jul/27/epublic.guardianweeklytechnologysection.

109 Directive 2007/2/EC of 14 March 2007 establishing an Infrastructure for Spatial Information in the European Community (INSPIRE). See http://www.ec-gis.org/inspire/directive/__10820070425en00010014.pdf. 